\title{
Utility of administrative and clinical data for cardiac surgery research: A case-based approach to guide choice
}

Tara Karamlou, MD, MSc, ${ }^{a}$ Michael J. Javorski, MD, ${ }^{b}$ Aaron Weiss, MD, ${ }^{b}$ Sara K. Pasquali, MD, MPH, ${ }^{c}$ and Karl F. Welke, MD, MS

"Don't use a screwdriver to pound a nail. It takes forever and wrecks the screwdriver." 1 This is a colloquial adaptation of Abraham Maslow's statement, "If your only tool is a hammer, every problem becomes a nail." 2 Tools for clinical research are evolving, including both eclectic information sources (data) and innovative analytic techniques. This is driven in part by regulatory bodies and third-party payers requiring healthcare personnel and hospitals to document the quality of care delivered. Valuebased care paradigms often require quality metrics be met for reimbursement. Further, reimbursements are correlated with published hospital reputation scores and performance statistics. In this Expert Opinion, we will examine the pearls and pitfalls of administrative and clinical data and subsequently illustrate appropriate use of each type of dataset to match specific clinical hypotheses in cardiothoracic surgery. Additionally, we pose a philosophical argument about the purpose of extraneous datasets and whether their use under a quality-assurance premise has simply intersected with or been supplanted by the use for research endeavors.

\section{ADMINISTRATIVE AND CLINICAL DATA: PEARLS AND PITFALLS \\ Administrative Data}

Administrative databases are typically thought of as originating in claims and billing (examples of administrative and clinical databases shown in Table 1). ${ }^{3-24}$ However, the broader definition of administrative data by the Organization for Economic Cooperation and Development ${ }^{25}$ is worth examining because it highlights some of the potential issues with these data sources. Administrative data have the following features:

\footnotetext{
From the Divisions of a Pediatric Cardiac Surgery and ${ }^{\mathrm{b}}$ Thoracic and Cardiovascular Surgery and the Heart Vascular and Thoracic Institute, Cleveland Clinic, Cleveland, Ohio; ' Division of Pediatric Cardiology, C. S. Mott Children's Hospital, University of Michigan, Ann Arbor, Mich; and ${ }^{\mathrm{d}}$ Division of Pediatric Cardiothoracic Surgery, Levine Children's Hospital/Atrium Health, Charlotte, NC.

Received for publication June 19, 2020; revisions received Sept 6, 2020; accepted for publication Sept 8, 2020; available ahead of print Oct 17, 2020.

Address for reprints: Tara Karamlou, MD, MSc, Division of Pediatric Cardiac Surgery, Cleveland Clinic, M41-022A, 9500 Euclid Ave, Cleveland, OH 44195 (E-mail: karamlt@ccf.org).

J Thorac Cardiovasc Surg 2021;162:1157-65

$0022-5223 / \$ 36.00$

Copyright (c) 2020 by The American Association for Thoracic Surgery

https://doi.org/10.1016/j.jtcvs.2020.09.135
}

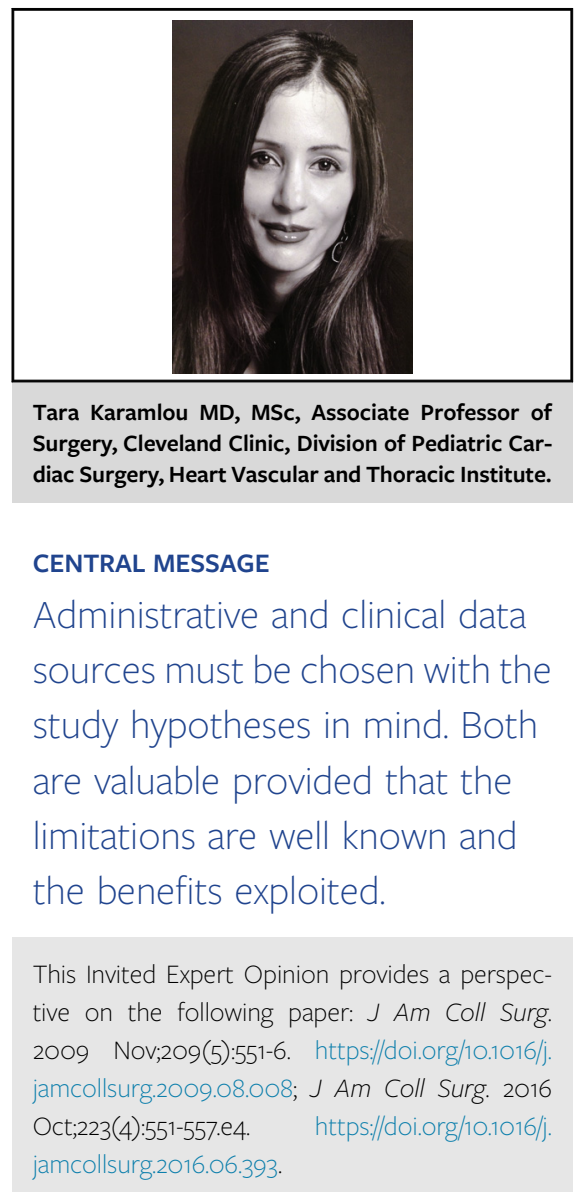

1. The agent supplying the data and the unit (in this case, the hospital) to which the data relate are usually different.

2. The data were originally collected for another reason (ie, repurposed for clinical research or quality improvement initiatives).

3. Complete coverage of a population (ie, large scope) is a central objective.

4. Control of the methods by which administrative data are collected reside with the agency.

Administrative data are typically inexpensive, readily available, and easier to collect, and often have a larger 
sample size. However, this data source may lack sufficient granularity, clinical information, and definitions to address a specific question; may be subject to a sampling design that limits the applicability to the desired population; may have such a large sample that statistical significance outpaces clinical significance; and may have a prohibitive number of coding errors. Several authors, including our group, have reported the scope of data errors found within administrative data and the ramifications of these errors as they relate to case ascertainment or estimates of outcome or performance. ${ }^{25-33}$ However, administrative data also have many desirable attributes that reduce informative bias, allow comprehensive cost analyses, and facilitate the study of rare conditions and national trends over time. The availability of certain unique patient-level or hospital-level data, including patient and hospital ZIP codes that may not be queried in some clinical data, is another benefit of using administrative data, either as an isolated source or as a complementary repository that can be linked with clinical data.

\section{Clinical Data}

On the other hand, clinical data, which for the most part in the field of cardiothoracic surgery in North America are embodied by the Society of Thoracic Surgeons (STS) family of databases, have their own pearls and pitfalls. Table 1 lists a collection of representative administrative and clinical databases relevant to cardiothoracic surgery. There are other clinical data sources that span related specialties, such as the cardiac intensive care-specific (Pediatric Cardiac Critical Care Consortium), or contain information about a specific group of patients (ie, Transcatheter Valve Therapy Registry or National Pediatric Cardiology Quality Improvement Collaborative), which will not be further discussed in this article. Vener and colleagues $^{34}$ chronicled a comprehensive list of 30 worldwide clinical databases and registries specific for congenital heart disease that includes surgery, cardiac critical care, and anesthesia. Clinical data generally have standardized definitions, and required STS data points, such as mortality and factors that populate mortality risk models, are validated internally (checked for consistency and absence of outliers) by a central data coordinating center and approximately $10 \%$ of centers are randomly selected for external audits conducted through a third-party contractor. The audit process is performed in person or remotely and includes pediatric cardiac surgeons and professional auditors. ${ }^{34-41}$ In 2013, an audit of the STS Congenital Heart Surgery Database (CHSD) documented accuracy percentages for the specified following fields of data: primary diagnosis $96.2 \%$, primary procedure $98.7 \%$, and 30 -day mortality $98.8 \%$. A linkage of the STS-Adult Cardiac Surgery Database (ACSDB) version 2.61 to the Social Security Death Master File for patients with nonmissing Social Security numbers $(\sim 62 \%)$ confirmed the accuracy of 30-day mortality data. ${ }^{35}$ The sensitivity for death before discharge was $98.8 \%$; however, sensitivity for death postdischarge was $59.7 \%$. Although $79 \%$ of deaths occurred before discharge, the incomplete capture of mortality at discharge is an important limitation that may be magnified when longer-term follow-up is incorporated into the STS registries as has been proposed. ${ }^{35}$ Highly accurate data for required fields coupled with strong commitment to iterative mortality risk-model development have culminated in multiple ACSDB mortality risk models (isolated coronary artery bypass grafting [CABG], isolated aortic valve replacement [AVR], isolated mitral valve replacement, isolated mitral valve repair, AVR $+\mathrm{CABG}$, mitral valve replacement $+\mathrm{CABG}$, and mitral valve repair $+\mathrm{CABG}$ ) with excellent discrimination (c-statistic of 0.75 or higher). ${ }^{37,38}$ The current STS CHSD mortality risk model also has excellent discrimination (c-statistics of 0.875). ${ }^{39-41}$ Despite the contributions that these mortality models represent, there remains critically important revisions to be addressed. The current STSCHSD risk-adjusted mortality models are based on procedures rather than diagnoses. ${ }^{40,41}$ Some correctly argue that this may provide suboptimal accounting for the differential risk of a procedure based on underlying diagnosis; for example, a Norwood procedure in a patient with hypoplastic left heart syndrome carries a greater risk of death than a Norwood procedure for tricuspid atresia with transposition and arch hypoplasia. This potential shortcoming, coupled with the perception that specific high-risk procedures concentrated at certain centers may not be captured accurately, has led to criticism, a revision of the public reporting platform, and initiatives to exploring alternative methods of risk adjustment.

\section{Case Ascertainment: When an Apple is an Orange}

Coding errors that result in case ascertainment bias may be more prevalent among CHS datasets due to diagnostic and procedural heterogeneity within CHS, relative rarity of complex procedures at any single institution, the high prevalence of multiple component operations, and the need to differentiate a fundamental congenital diagnosis from the current indication for intervention. A good example of this is an adult patient with repaired tetralogy of Fallot who returns decades later for a pulmonary valve replacement due to free pulmonary insufficiency. Although it is important to capture the fundamental diagnosis of tetralogy of Fallot, the current procedure, pulmonary valve replacement, should be linked to a diagnosis of pulmonary valve insufficiency. This is especially critical in administrative data where linking of diagnosis with procedure codes is used to reduce the impact of coding errors in clinical research. Pasquali and colleagues ${ }^{29}$ used a linked STS-CHSD-Pediatric Health Information Systems (PHIS) administrative dataset to compare case ascertainment among 
TABLE 1. List of administrative and clinical databases with details on access to the databases

\begin{tabular}{|c|c|}
\hline Administrative databases & Access \\
\hline Agency for Healthcare Research and Quality hospital discharge data & $\begin{array}{l}\text { Public access through HCUP. Requires study form and CITI training. } \\
\text { Fee schedule varies. }\end{array}$ \\
\hline Canadian Institute for Health Information & $\begin{array}{l}\text { Open access to reports on aggregate level data. Specific data requests } \\
\text { priced on a cost-recovery basis. }\end{array}$ \\
\hline Children's Health Insurance Program & Open access $^{5}$ \\
\hline Hospital Episode Statistics & Data request priced on cost recovery basis ${ }^{6}$ \\
\hline Kids' Inpatient Database, part of HCUP data & $\begin{array}{l}\text { Able to purchase/access HCUP data after completing a training course } \\
\text { and signing data use agreement. }\end{array}$ \\
\hline Medicaid data & Open access $^{5}$ \\
\hline Medicare data & Open access ${ }^{8}$ \\
\hline NIS, part of HCUP data & $\begin{array}{l}\text { Able to purchase/access HCUP data after completing a training course } \\
\text { and signing data use agreement. }\end{array}$ \\
\hline PHIS & Access to CHA membership. ${ }^{10}$ \\
\hline Veterans Affairs & Open access for public data. ${ }^{11}$ \\
\hline Vizient, formerly University HealthSystem Consortium & Access after membership enrollment. ${ }^{12}$ \\
\hline National Death Index & $\begin{array}{l}\text { Centralized database available only for statistical purposes in medical } \\
\text { and health research to track vital statistics for study patients from } \\
1979 \text { to present. }{ }^{13}\end{array}$ \\
\hline Social Security Death Master File & Registration required. Payment per record. ${ }^{14}$ \\
\hline
\end{tabular}

\begin{tabular}{|c|c|}
\hline Clinical databases & \\
\hline CHSS & $\begin{array}{l}\text { Participation limited to CHSS centers. Academic datasets with } \\
\text { prospective annual follow-up. }{ }^{15}\end{array}$ \\
\hline $\begin{array}{l}\text { European Association for Cardio-Thoracic Surgery Adult Cardiac } \\
\text { Surgical Database }\end{array}$ & $\begin{array}{l}\text { Access for surgeons from participating hospitals. Data reports published } \\
\text { annually. }{ }^{16}\end{array}$ \\
\hline Improving pediatric and adult congenital treatment database & Access requires registration. ${ }^{17}$ \\
\hline Pediatric Cardiac Critical Care Consortium & $\begin{array}{l}\text { Data provided to participating hospitals. Outside users may need to } \\
\text { request access. }{ }^{18}\end{array}$ \\
\hline $\begin{array}{l}\text { STS National Database (adult cardiac surgery, congenital heart surgery } \\
\text { [including anesthesia module of STS and Congenital Cardiac } \\
\text { Anesthesia Society], general thoracic surgery and Intermacs and } \\
\text { Pedimacs databases) }\end{array}$ & Requires data request. ${ }^{19}$ \\
\hline Surveillance, Epidemiology, and End Results database & Public access, fees vary. ${ }^{20}$ \\
\hline Transcatheter Valve Therapy Registry & Requires data request. ${ }^{21}$ \\
\hline $\begin{array}{l}\text { National Pediatric Cardiology Quality Improvement Collaborative } \\
\text { (specific for tracking patients with hypoplastic left heart syndrome) }\end{array}$ & Participation by 68 centers within the collaborative. ${ }^{22}$ \\
\hline $\begin{array}{l}\text { Advanced Cardiac Therapies Improving Outcomes network (congenital } \\
\text { heart failure registry) }\end{array}$ & $\begin{array}{l}\text { Registry data available to participating sites, limited to pediatric heart } \\
\text { failure centers. }\end{array}$ \\
\hline Extracorporeal Life Support Organization Registry & $\begin{array}{l}\text { Patients undergoing ECMO are included from } 298 \text { programs worldwide. } \\
\text { Price for data varies by country. }{ }^{24}\end{array}$ \\
\hline
\end{tabular}

HCUP, Healthcare Cost and Utilization Project; CITI, Collaborative Institutional Training Initiative; NIS, National Inpatient Sample; PHIS, Pediatric Health Information System; CHA, Children's Hospital Association; CHSS, Congenital Heart Surgeons Society; STS, Society of Thoracic Surgeons; ECMO, extracorporeal membrane oxygenation.

benchmark congenital cardiac operations and mortality rates. When the International Classification of Diseases 9th Revision (ICD-9) procedure codes were used alone, volumes of certain cases, ventricular septal defect (VSD) repair for example, were inflated relative to the STS-CHSD, which was considered the gold standard. $\mathrm{We}^{42-46}$ and others have used diagnosis codes in conjunction with procedural codes to improve fidelity and reduce these types of errors.
Several studies have also used aggregation into more homogeneous risk groups to mitigate case ascertainment bias in both administrative and clinical databases. ${ }^{29,37,41-46}$

Adult cardiac surgery studies, capitalizing on larger case volumes within procedural groups and enhanced homogeneity, have shown improved matching fidelity among administrative and clinical databases. Shahian and colleagues $^{47}$ found a $27 \%$ disparity when comparing 
Massachusetts clinical registry data with a state administrative database for isolated CABG cases with case volume inflation again noted administrative data. Although this is not an inconsequential difference, this is improved from the $40.5 \%$ underestimation in the CHS mortality estimates when comparing administrative to the STS-CHSD. ${ }^{27}$ Likewise, Prasad and colleagues ${ }^{48}$ reported only $2 \%$ to $12 \%$ more cases for AVR, mitral valve replacement, and CABG in the University HealthSystem Consortium database compared with the STS-ACSDB.

\section{Outcome Prediction: Garbage In, Garbage Out}

As we have mentioned, administrative databases use a uniform, limited hospital discharge dataset from which basic demographics, International Classification of Diseasesbased diagnosis and procedure codes, mortality, length of stay, and cost can be determined. ${ }^{27,42,44,46}$ Administrative data are based on a hospital admission or encounter in which the admission rather than the patient is the captured unit. Although this may seem to be a trivial distinction, it may result in "double-counting" an individual patient who has multiple admissions to the same hospital. Patient data are captured as "many-to-one" with multiple comorbidities, diagnoses, and procedures assigned, although usually referenced to an "index" or principal diagnosis or procedure. One concern is the lack of time-date stamping in administrative data such that differentiation of a comorbid condition from a treatment complication may prove difficult. $^{27,42,44,46,49-52}$ Although the former can and should be used for risk assessment and prediction, the latter should not be included because complications are often within the final common pathway to an adverse outcome and are also outcomes within themselves. The inclusion of postoperative complications in a model that purportedly uses preoperative factors to calculate risk of postoperative events will falsely increase the ability of the model to do so. Exclusion of postoperative complications from the University HealthSystem Consortium mortality risk model decreased the model's discrimination significantly from a c-statistic of 0.88 to $0.49 .{ }^{49}$ A c-statistic of 0.88 suggests a model that can accurately determine which patients will live or die while 0.49 equates to a coin flip. In contrast, the STS-ACSDB mortality risk model performance was only marginally reduced, from a c-statistic of 0.81 to 0.79 .

Some administrative data use the $3 \mathrm{M}$ all-patients refined diagnosis-related group system to provide adjustments for patient severity. ${ }^{49-53}$ This system assigns the lowest severity of illness level and mortality risk to complications in an effort to reduce the impact of ambiguity in distinguishing between preoperative factors and postoperative events. However, this partial measure has not resulted in this problem being meaningfully mitigated. ${ }^{49,50}$ Stemming from pressure to provide fair risk adjustment to inform pay-for-performance policy, the
Centers for Medicare and Medicaid now require implementation of a flag, "Present on Admission," that can be attached to patient factors or events to help ameliorate this liability. Whether these modifications will translate into meaningful improvements in model performance, especially with the introduction of International Classification of Diseases 10th Revision (ICD-10) coding remains unclear. The disruption that ICD-10 code implementation has created in terms of the utility of administrative data for CHS investigations cannot be overstated. Since 2002, the Risk Adjustment for Congenital Heart Surgery, version 1 (RACHS-1), a consensus-based system, has been the standard for CHS risk assessment in administrative data. ${ }^{27,29,52-54}$ The STS-European Association for Cardio-Thoracic Surgery CHS Mortality or STAT Score has been the analogous standard for clinical data (although STAT is empirically derived) since 2009, but the STAT scores and categories have not been mapped to ICD-10-Clinical Modification (CM) codes, an important step that could facilitate linkage. Because RACHS-1 was developed for ICD-9-CM data, the change to ICD-10-CM has invalidated the algorithm to calculate RACHS- 1 codes. This is a significant impediment because there is now no way to fairly adjust for case mix or patient complexity in administrative data.

Current projects are under way that will provide new mapping algorithms and greater coverage for procedures that were not in widespread use at the time RACHS- 1 was developed (ie, hybrid stage-1 palliation). Further, given that STAT scores are empirically derived and RACHS-1 was consensus based, new mapping algorithms may provide insight as to harmonizing these 2 risk-stratification systems.

Williams and McCrindle ${ }^{55}$ characterized differences among types of data in the statement, "A database is simply a structured collection of information. A clinical database may be a registry (a limited amount of data for every patient undergoing heart surgery) or academic (an organized and extensive dataset of an inception cohort of carefully selected subset of patients). A registry and an academic database have different purposes and cost." Lack of data granularity is a common critique of administrative data. Although these datasets contain an abbreviated number of variables, clinical databases also contain limits to the data that are captured. Neither the STS nor administrative databases contain imaging or hemodynamic data, which are important to include for accurate risk stratification for complex operations. How can one assess candidacy for a Fontan operation without knowing the systemic ventricular end-diastolic pressure or the status of the pulmonary vasculature? The STS Predicted Risk of Mortality scores for isolated AVR contain more variables than the CHSD STAT scores, but many of these variables are binary and therefore lack the additional precision afforded by 
continuous variables such as echocardiographic measurements or hemodynamics.

Lack of longitudinal follow-up is another limitation of both administrative and clinical registry data, because follow-up is usually truncated to hospital discharge or 30 days postdischarge. Addition of a unique patient identifier would help in tracing intermediate and longterm outcomes only for the group of patients readmitted to a hospital participating in the registry. Intermediate and long-term follow-up information for patients readmitted to hospitals outside of the registry would not be captured by this modification. Because overall STS-defined operative mortality is low $\left(2.8 \%{ }^{56}\right.$ for CHS and $1 \%-2 \%$ for adult cardiac surgery), neurodevelopmental outcomes, health-related quality of life, and metrics that reflect the long-term durability of the operation are of primary concern to more than $97 \%$ of patients. Whether these types of resource-intensive longitudinal measures are more appropriately captured in center-specific registries or as components of dedicated research initiatives is a major question that may become more pressing as resources become increasingly limited and database participation fatigue ensues. Efforts to streamline data collection for mandated national registries (ie, the proposed American Association for Thoracic Surgery quality database) or leverage automated abstraction from patient-driven platforms such as Epic's "MyChart" highlight current trends away from embellished variable lists or reporting. The STS National Database has recently decreased the number of data fields in an effort to reduce data-entry burden and is exploring mechanisms to abstract data directly from the electronic medical record. Assembling a unified network of participating databases is another method that should minimize redundancies and streamline regulatory and surveillance processes. Cardiac Networks United $^{57}$ provides an organizational structure that coordinates the efforts of 5 congenital databases (and likely others will follow). This effort aims to harmonize data collection and reduce redundancies, and provides a mechanism to integrate in-hospital outcomes with longitudinal outcome data like neurodevelopmental outcomes through the cardiac neurodevelopmental outcomes collaborative and quality of life data through the patient-reported outcomes module. Such collaborative endeavors will undoubtedly facilitate cooperative learning and catalyze scientific progress.

We have outlined some of the pitfalls of both administrative and clinical data, but a few pearls are worth mentioning. First, administrative data benefits from large numbers of patients and hospitals $\mathrm{s}^{27,44,46,49,53}$ and are inclusive by design. They either include all hospitals within a specified geographic area, such as state-level databases, or use a stratified sampling design that allows a fixed percentage of hospitals to accurately represent the entire sampling "universe."27,44,49,53 This sampling scheme facilitates generalization of findings to the larger population from whom the sample was selected. Further, by including information from both high- and low-performing and high- and low-volume hospitals, administrative data can be used to evaluate the practice patterns and performance of hospitals that are less likely to participate in large, voluntary clinical databases. The wider scope of administrative data was evident from our regionalization articles ${ }^{58,59}$ that identified 153 hospitals in the United States at which CHS was performed; $22 \%$ more than participate in the STS-CHSD. Large sample sizes inherent in administrative datasets enhance the robustness of multivariable models to missing data and offer opportunities to study rare diseases and trends across time. A word of caution, however, statistical power to detect differences among groups is magnified by the often enormous sample sizes in administrative data. Findings therefore require clinical context before inferences about superiority or inferiority can be made.

\section{Mortality Estimates}

Mortality estimates are affected by differential case ascertainment (ie, lack of concordance between the numbers of cases captured), the inappropriate coding of multicomponent procedures as a single component rather than the complete repair, and the availability of variables that can be used in risk-adjusted models. Consideration of the impact of hospital and surgeon factors that will be constrained by the type of data will also alter model performance. We will restrict our discussion to mortality because it is the metric most commonly used for benchmarking and public reporting, although clearly, other in-hospital outcomes such as morbidity and length of stay also depend on these aforementioned factors. In general, mortality estimates obtained from administrative databases that sample from defined geographic regions (ie, the Healthcare Cost and Utilization Project family of datasets) ${ }^{60}$ are higher than those obtained from clinical registries such as the STS. The discordance in estimates (ie, assigning higher or lower mortality compared with what would have been estimated without coding errors or case ascertainment errors) is more pronounced for simple procedures or complex procedures with multiple components. ${ }^{27,29}$ For example, one CHS study reported $26 \%$ underestimation of mortality with truncus arteriosus repair and a $31 \%$ overestimation of mortality with VSD repair in the PHIS dataset compared with the STS-CHSD. ${ }^{29}$ Coding of complex or multicomponent operations is challenging in administrative data because some procedures (eg, the Norwood operation) do not have a dedicated ICD-CM procedure code. Therefore, the Norwood is deconstructed into multiple components such as right ventricle-to-pulmonary artery conduit and coarctation 
repair, which in isolation have lower mortality than the comprehensive procedure. Alternatively, for procedures in which dedicated ICD-CM procedure codes do exist, such as for truncus arteriosus, abstracters may choose the recognizable or more common code such as VSD closure, which then erroneously assigns the higher mortality estimate to the aggregate VSD group and lowers the estimated mortality for the truncus arteriosus group. As anticipated, this phenomenon would lower the volume of high complexity procedures in administrative data and increase the number of lower complexity procedures, which is exactly what Pasquali and colleagues ${ }^{29}$ documented (19\% less operations categorized in the highest complexity group, RACHS-6). Selective reporting of higher-volume hospitals or those with optimal performance to clinical registries also may increase the aggregate mortality estimates obtained from administrative data, which are more inclusive. Welke and colleagues ${ }^{27}$ used membership in the Congenital Heart Surgery Society as a surrogate for quality or high-performing CHS hospitals. CHS mortality estimates from 2 administrative databases, the Kids' Inpatient Database and Nationwide Inpatient Sample (NIS), were higher than that from the selected, presumed high-performing centers. Similar examples have been reported in adult cardiac surgery with administrative data estimates higher than those obtained from the STS-ACSDB. ${ }^{46,47,49-51,60,61}$

Not all discrepancies in mortality rates are due to case ascertainment or allocation errors. Some may be due to follow-up of patients beyond the 30-day window used currently by the STS registries. Welke and colleagues ${ }^{51}$ looked at patients aged more than 65 years undergoing CABG, AVR, or mitral valve replacement and compared mortality rates from the STS-ACSDB to administrative claims data in the Medicare Provide Analysis and Review. In-hospital mortality rates were similar between the 2 databases, although slightly lower in the STS. The 30-day mortality was also lower in the STS-ACSDB compared with the Medicare Provide Analysis and Review database because Medicare Provide Analysis and Review tracks patients after the hospitalization with Medicare enrollment files, increasing the accuracy of these posthospital events. ${ }^{51}$ There is interest in the implementation of 1-year follow-up metrics in the STS registries, but whether this is feasible for centers with national or international catchment areas or limited resources to track patients remains unclear. However, one could argue that if a center has the resources to operate on an international patient, the center should have the resources and responsibility to ascertain whether or not that same patient is alive 1 year after surgery. Appropriate allocation of a patient's death to the center in which the index operation occurred is also problematic with longer-term cross-sectional follow-up because of the lack of accounting for intervening events and patient compliance. Some would argue that longer-term statistics, along with quality of life, neurodevelopment, changes in hemodynamics, or prosthesis function over time, should be reserved for research purposes and that these cannot be accurately investigated in clinical registries without prohibitive cost that could further discourage participation among the full spectrum of hospitals. Although short-term mortality is easily collected, in isolation it provides a fragment of the patient experience and should be augmented by longer-term metrics. For further reference, Table 2 catalogues a collection of recent articles that contrast administrative and clinical data.

It is important to mention that both administrative and STS databases use discharge mortality or 30-day mortality as the outcome metric. Although the use of these short-term metrics may increase the accuracy of patient status, they are limited and arbitrary. As pointed out by Williams and McCrindle ${ }^{55}$ the early hazard for patient death after operation is not affected by hospital discharge or the 30-day period. The inclusion of 1-year survival as an outcome that will likely be implemented by the STS family of databases, provided appropriate oversight and auditing are feasible, is a significant improvement that will allow more robust analyses of performance and quality.

\section{CASE VIGNETTES}

\section{Case 1: Aortic Valve Replacement: Clarifying the Current and Potential Future Roles for Transcatheter Aortic Valve Replacement}

Nelson and colleagues ${ }^{67}$ recently examined different treatment approaches for AVR. They sought to define practice patterns for AVR in adults aged less than 55 years by determining mortality and morbidity over a 5 -year period. What dataset should the authors choose?

To address this complex question, a dataset with granular information regarding patient risk factors, such as associated coronary artery disease, concomitant mitral disease or aortic aneurysm, number of prior sternotomies, aortic annular size, presence of endocarditis, and surgeon and hospital factors such as case volumes, is critical. Although some comorbidities may be present in administrative data as we have discussed, the severity of associated cardiac conditions is not coded; therefore, only those lesions severe enough to warrant a concomitant operation would be captured through the matching of procedure and diagnosis codes. Moreover, procedure-specific factors are also important in estimating mortality, such as cannulation strategy, hematocrit, myocardial protection, implanted prosthesis type, and prosthesis size. The majority of these variables are not coded in administrative data but are available in the STS databases. National practice patterns over time 
TABLE 2. List of publications comparing administrative and clinical databases

\begin{tabular}{|c|c|c|c|}
\hline Authors & Year of publication & Databases compared & Data compared \\
\hline Aylin and colleagues ${ }^{52}$ & 2007 & HES (administrative) vs SCTS (clinical) & Comparison of risk prediction models \\
\hline Bortolussi and colleagues $^{49}$ & 2019 & PAS (administrative) vs PATS (clinical) & Case ascertainment \\
\hline Jacobs and colleagues $^{62}$ & 2010 & STS vs CMS & CABG case ascertainment \\
\hline Jacobs and colleagues $^{63}$ & 2011 & STS vs SSDMF & Survival data \\
\hline Jacobs and colleagues ${ }^{40}$ & 2013 & STS ACSD vs SSDMF & Mortality \\
\hline Jacobs and colleagues $^{64}$ & 2016 & STS vs CMS & CABG case ascertainment \\
\hline Jacobs and colleagues $^{65}$ & 2017 & SSDMF vs EVVE vs NDI & $\begin{array}{l}\text { Editorial comparing databases reporting vital } \\
\text { status }\end{array}$ \\
\hline Jantzen and colleagues $^{30}$ & 2014 & STS-CHSD vs PHIS & $\begin{array}{l}\text { Case ascertainment, postoperative length of stay, } \\
\text { and cost }\end{array}$ \\
\hline Kozower and colleagues ${ }^{50}$ & 2009 & UHC vs STS ACSD & Comparison of risk prediction models \\
\hline Mack and colleagues ${ }^{61}$ & 2005 & STS ACSD vs multiple administrative databases & CABG outcomes \\
\hline Pasquali and colleagues ${ }^{29}$ & 2013 & STS CHSD vs PHIS & Case ascertainment and mortality \\
\hline Pasquali and colleagues ${ }^{46}$ & 2015 & STS CHSD vs PHIS & Case ascertainment and mortality \\
\hline Prasad and colleagues ${ }^{48}$ & 2016 & STS ACSD vs UHC & Case ascertainment and surgical outcomes \\
\hline Shahian and colleagues ${ }^{47}$ & 2007 & Massachusetts clinical registry vs AHRQ data & Isolated CABG data from discharge dataset \\
\hline Tong and colleagues ${ }^{66}$ & 2019 & STS GTSD vs CMS & Lobectomy case ascertainment and outcomes \\
\hline Welke and colleagues ${ }^{28}$ & 2004 & STS ACSD vs MedPAR Part A public use data & Case ascertainment and outcomes \\
\hline Welke and colleagues ${ }^{51}$ & 2007 & STS ACSD vs MedPAR & Case ascertainment and mortality \\
\hline Welke and colleagues $^{27}$ & 2009 & NIS and KID vs STS and CHSS & Surgical mortality in pediatric cardiac surgery \\
\hline
\end{tabular}

The authors, year of publication, databases, and data measures that are compared are detailed. HES, Hospital Episode Statistics; SCTS, Society of Cardiothoracic Surgeons; PAS, Patient Administrative System; PATS, Patient Administrative and Tracking System; STS, Society of Thoracic Surgeons; CMS, Center for Medicare and Medicaid Services; $C A B G$, coronary artery bypass grafting; SSDMF, Social Security Death Master File; STS ACSD, Society of Thoracic Surgeons Adult Cardiac Surgery Database; EVVE, Electronic Verification of Vital Events; NDI, National Death Index; STS CHSD, Society of Thoracic Surgeons Congenital Heart Surgery Database; PHIS, Pediatric Health Information System; UHC, University HealthSystem Consortium; AHRQ, Agency for Healthcare Research and Quality; GTSD, General Thoracic Surgery Database; MedPAR, Medicare Provider and Analysis Review; NIS, National Inpatient Sample; KID, Kids' Inpatient Database; CHSS, Congenital Heart Surgeon Society.

could have been addressed by including multiple years of administrative or clinical data, but less common (and more recently introduced) procedures such as the Ozaki or Ross-Konno may be more accurately coded in the STS-ACSDB. Annual AVR center volume could be abstracted from some administrative dataset such as the State Inpatient Databases (SID); however, others including the Kids' Inpatient Database and the NIS use a sampling scheme that harvests an $80 \%$ sample of discharges. Furthermore, consecutive years of an administrative dataset such as the NIS may not include the same hospitals within the sampling scheme, limiting the ability to track specific hospital's volumes across time. Surgeon volumes are readily abstracted from administrative data using a discrete variable, Surgeon-ID, which is distinct from the other variable, PhY-ID, which indicates the admitting or treating physician. Note that cost was not included in the outcomes studied. Had the authors wanted to investigate cost, an administrative dataset or a linkage between administrative and clinical data as was done in the linkage between the STS and PHIS ${ }^{29}$ would be needed because these measures are not captured by the STS registries.

\section{Case 2: Regionalization of Congenital Cardiac Surgery Care}

The question posed by these authors ${ }^{58,59}$ was whether a system in which all hospitals in the United States providing CHS were consolidated on the basis of different thresholds, either annual case volume or case complexity, would lead to a reduction in in-hospital mortality without a prohibitive increase in patient travel distance. What dataset should be chosen to address this problem?

The dataset must include all CHS hospitals, even very low-volume hospitals, and provide the ZIP code of each hospital and each patient so that travel distances can be determined. Finally, risk stratification is needed to adjust for case mix in mortality models so that patients can be regionalized on the basis of case complexity. This analysis is best accomplished using administrative data, but of all available types of administrative data, only the SID contains ZIP code level information for both patients and hospitals as well as every hospital discharge within each center rather than a sample of discharges. Every SID must be obtained and concatenated to create a national dataset capable of answering the questions posed. Procedure codes should be 
linked to diagnosis codes to reduce coding errors and case ascertainment biases as we have discussed. Note that risk adjustment and case complexity assignment were possible for this analysis by mapping ICD-9-CM codes to the RACHS-1 system. The STS-CHSD could have provided some of the data required, such as high-fidelity center case volumes and accurate risk-adjustment models, but clinical registries such as the STS would have excluded the hospitals that are a primary focus of regionalization initiatives: lower-volume hospitals or those hospitals that may report under the umbrella of a larger center.

\section{CONCLUSIONS}

Both clinical and administrative data are valuable but generally can answer different questions. Therefore, the type of data chosen for each study must be based on a comprehensive knowledge of the inherent pearls and pitfalls of each dataset. Optimum study designs will exploit the benefits and structure of a particular dataset as they relate to the specific hypotheses posed. By doing so, we can maximize the discovery of new knowledge and move closer to what Helen Deutsch stated eloquently is the purpose of scientific study, "... the ultimate goal of all research is not objectivity, but truth." ${ }^{\circ 8}$

\section{Conflict of Interest Statement}

The authors reported no conflicts of interest.

The Journal policy requires editors and reviewers to disclose conflicts of interest and to decline handling or reviewing manuscripts for which they may have a conflict of interest. The editors and reviewers of this article have no conflicts of interest.

\section{References}

1. Anonymous. Available at: www.wiki.c2.com. Accessed June 1, 2020.

2. Maslow A. Toward a Psychology of Being. New York, NY: John Wiley \& Sons; 1962.

3. Agency for Healthcare Research and Quality. Healthcare cost and utilization project (HCUP). Available at: http://www.ahrq.gov/data/hcup/index.html. Accessed June 15, 2020.

4. Canadian Institute for Health Information. Access data and reports | CIHI. Available at: https://www.cihi.ca/en/access-data-and-reports. Accessed June 14, 2020.

5. Centers for Medicare \& Medicaid Services. Data.Medicaid.gov Centers for medicare and medicaid services. Available at: https://data.medicaid.gov/. Accessed June 14, 2020.

6. National Health Service. Data access request service (DARS) charges from 2020/ 2021. NHS digital. Available at: https://digital.nhs.uk/services/data-accessrequest-service-dars/data-access-request-service-dars-charges. Accessed June 14, 2020.

7. Agency for Healthcare Research and Quality. KID database documentation. Available at: https://www.hcup-us.ahrq.gov/db/nation/kid/kiddbdocumentation. jsp. Accessed June 14, 2020.

8. Centers for Medicare \& Medicaid Services. Archived datasets | Data.Medicare. gov. Data.Medicare.Gov. Available at: https://data.medicare.gov/data/archives/ hospital-compare. Accessed June 14, 2020.

9. Agency for Healthcare Research and Quality. NIS database documentation. Available at: https://www.hcup-us.ahrq.gov/db/nation/nis/nisdbdocumentation. jsp. Accessed June 14, 2020.
10. Children's Hospital Association. PHIS. Available at: https://www.childrens hospitals.org/phis. Accessed June 14, 2020.

11. US Department of Veterans Affairs. Department of Veterans Affairs Open Data Portal. Socrata. Available at: https://va.data.socrata.com/. Accessed June 14, 2020.

12. Vizient. CDB | healthcare analytics platform for clinical benchmarking. Available at: https://www.vizientinc.com/our-solutions/clinical-solutions/clinicaldata-base. Accessed June 14, 2020.

13. Centers for Disease Control and Prevention. National Death Index. Available at: https://www.cdc.gov/nchs/ndi/index.htm. Accessed July 29, 2020.

14. Social Security Administration. Data exchange. 2020/ndi/indSA's death information. Available at: https://www.ssa.gov/dataexchange/request_dmf.html. Accessed June 15, 2020.

15. Congenital Heart Surgeons' Society. CHSS data center: Welcome to the CHSS data center. Available at: https://data-center.chss.org/. Accessed June 15, 2020.

16. European Association for Cardio-Thoracic Surgery. EACTS Quality Improvement Programme. Adult cardiac database. EACTS. Available at: https://www. eacts.org/quip/adultcardiacdatabase/. Accessed June 14, 2020.

17. American College of Cardiology Quality Improvement for Institutions. IMPACT registry. Available at: https://cvquality.acc.org/NCDR-Home/registries/hospitalregistries/impact-registry. Accessed June 15, 2020.

18. Pediatric cardiac critical care consortium $\left(\mathrm{PC}^{4}\right)$. Available at: https://pc4quality org/. Accessed June 14, 2020.

19. The Society of Thoracic Surgeons. Access \& publications | STS. Available at: https://www.sts.org/registries-research-center/sts-research-center/access-publications. Accessed June 14, 2020.

20. National Institutes of Health. National Cancer Institute. SEER incidence database - SEER data \& software. SEER. Available at: https://seer.cancer.gov/data/ index.html. Accessed June 15, 2020.

21. American College of Cardiology. FAQs. Available at: https://www.ncdr.com/ WebNCDR/tvt/publicpage/faqs. Accessed June 15, 2020.

22. National Pediatric Cardiology Quality Improvement Collaborative. NPC-QIC. Available at: https://www.npcqic.org. Accessed June 18, 2020.

23. Advanced Cardiac Therapies Improving Outcomes Network. Our collaborative. Available at: http://actionlearningnetwork.org/collaborative. Accessed June 19, 2020.

24. Extracorporeal Life Support Organization. ELSO. Available at: http://www.elso. org. Accessed July 30, 2020.

25. Organisation for Economic Co-operation and Development. OECD. Short-term economic statistics (STES) administrative data: two frameworks of papers; 2016. Available at: http://www.oecd.org/std/shorttermeconomicstatisticsstes administrativedatatwoframeworksofpapers.htm\#Definition. Accessed June 2, 2020.

26. Hand DJ. Statistical challenges of administrative and transaction data. J R Stat Soc Series A. 2018;181:555-605.

27. Welke KF, Diggs BS, Karamlou T, Ungerleider RM. Comparison of pediatric cardiac surgical mortality rates from national administrative data to contemporary clinical standards. Ann Thorac Surg. 2009;87:216-23.

28. Welke KF, Ferguson TB, Coombs LP, Dokholyan RS, Murray CJ, Schrader MA, et al. Validity of the Society of Thoracic Surgeons National adult cardiac surgery database. Ann Thorac Surg. 2004;77:1137-9.

29. Pasquali SK, Peterson ED, Jacobs JP, He X, Li JS, Jacobs ML, et al. Differential case ascertainment in clinical registry versus administrative data and impact on outcomes assessment for pediatric cardiac operations. Ann Thorac Surg. 2013;95:197-203.

30. Jantzen DW, He X, Jacobs JP, Jacobs ML, Gaies MG, Hall M, et al. The impact of differential case ascertainment in clinical registry versus administrative data on assessment of resource utilization in pediatric heart surgery. World J Pediatr Congenit Heart Surg. 2014;5:398-405.

31. Cronk CE, Malloy ME, Pelech AN, Miller RE, Meyer SA, Cowell M, et al. Completeness of state administrative databases for surveillance of congenital heart disease. Birth Defects Res A Clin Mol Teratol. 2003;67:597-603.

32. Frohnert BK, Lussky RC, Alms MA, Mendelsohn NJ, Symonik DM, Falken MC Validity of hospital discharge data for identifying infants with cardiac defects. $J$ Perinatol. 2005;25:737-42

33. Strickland MJ, Riehle-Colarusso TJ, Jacobs JP, Reller MD, Mahle WT, Botto LD, et al. The importance of nomenclature for congenital cardiac disease: implications for research and evaluation. Cardiol Young. 2008;18(Suppl 2):92-100.

34. Vener DF, Gaies M, Jacobs JP, Pasquali SK. Clinical databases and registries in congenital and pediatric cardiac surgery, cardiology, and anesthesiology worldwide. World J Pediatr Congenit Heart Surg. 2017;8:77-87. 
35. Society of Thoracic Surgeons. Society of Thoracic Surgeons Congenital Heart Surgery Database executive summary report. Available at: https://www.sts.org/ registries-research-center/sts-national-database/sts-national-database-audits. Accessed June 14, 2020

36. Overman DM, Jacobs ML, O’Brien JE, Kumar SR, Mayer JE, Ebel A, et al. Ten years of data verification: the Society of Thoracic Surgeons congenital heart surgery database audits. World J Pediatr Congenit Heart Surg. 2019;10:454-63.

37. O'Brien SM, Feng L, He X, Xian Y, Jacobs JP, Badhwar V, et al. The Society of Thoracic Surgeons 2018 adult cardiac surgery risk models: part 2- statistical methods and results. Ann Thorac Surg. 2018;105:1419-28.

38. Shahian DM, Jacobs JP, Badhwar V, Kurlansky PA, Furnary AP, Cleveland JC, et al. The Society of Thoracic Surgeons 2018 adult cardiac surgery risk models: part 1- background, design considerations, and model development. Ann Thorac Surg. 2018;105:1411-8

39. Jacobs JP, O'Brien SM, Hill KD, Kumar SR, Austin EH, Gaynor JW, et al. Refining the Society of Thoracic Surgeons congenital heart surgery database risk model with enhanced risk adjustment for chromosomal abnormalities, syndromes, and noncardiac congenital anatomic abnormalities. Ann Thorac Surg. 2019; 108:558-66.

40. Jacobs JP, O'Brien SM, Shahian DM, Edwards FH, Badhwar V, Dokholyan RS, et al. Successful linking of the Society of Thoracic Surgeons database to social security data to examine the accuracy of Society of Thoracic Surgeons mortality data. J Thorac Cardiovasc Surg. 2013;145:976-83.

41. Jacobs JP, O’Brien SM, Pasquali SK, Gaynor JW, Mayer JE, Karamlou T, et al. The Society of Thoracic Surgeons congenital heart surgery database mortality risk model: part 2- clinical applications. Ann Thorac Surg. 2015;100:1063-8.

42. Karamlou T, Diggs BS, Person T, Ungerleider RM, Welke KF. National practice patterns for management of adult congenital heart disease: operation by congenital surgeons decreases in-hospital death. Circulation. 2008;118:2345-52.

43. Welke KF, Karamlou T, Diggs BS. Databases for assessing the outcomes of the treatment of patients with congenital and paediatric cardiac disease - a comparison of administrative and clinical data. Cardiol Young. 2008;18(Suppl 2):137-44.

44. Karamlou T, Diggs BS, McCrindle BW, Ungerleider RM, Welke KF. The rush to atrial septal defect closure: is the advent of percutaneous closure driving utilization? Ann Thorac Surg. 2008;86:1584-90.

45. Welke KF, Diggs BS, Karamlou T, Ungerleider RM. Measurement of quality in pediatric cardiac surgery: understanding the threats to validity. ASAIO J. 2008; 54:447-50.

46. Pasquali SK, He X, Jacobs JP, Jacobs ML, Gaies MG, Shah SS, et al. Measuring hospital performance in congenital heart surgery: administrative versus clinical registry data. Ann Thorac Surg. 2015;99:932-8.

47. Shahian DM, Silverstein T, Lovett AF, Wolf RE, Normand S-LT. Comparison of clinical and administrative data sources for hospital coronary artery bypass graft surgery report cards. Circulation. 2007;115:1518-27.

48. Prasad A, Helder MR, Brown DA, Schaff HV. Understanding differences in administrative and audited patient data in cardiac surgery: comparison of the University HealthSystem Consortium and Society of Thoracic Surgeons databases. $J$ Am Coll Surg. 2016;223:551-7.e4.

49. Bortolussi G, McNulty D, Waheed H, Mawhinney JA, Freemantle N, Pagano D. Identifying cardiac surgery operations in hospital episode statistics administrative database, with an OPCS-based classification of procedures, validated against clinical data. BMJ Open. 2019;9:e23316.

50. Kozower BD, Ailawadi G, Jones DR, Pates RD, Lau CL, Kron IL, et al. Predicted risk of mortality models: surgeons need to understand limitations of the University HealthSystem Consortium models. J Am Coll Surg. 2009;209:551-6.

51. Welke KF, Peterson ED, Vaughan-Sarrazin MS, O'Brien SM, Rosenthal GE, Shook GJ, et al. Comparison of cardiac surgery volumes and mortality rates between the Society of Thoracic Surgeons and Medicare databases from 1993 through 2001. Ann Thorac Surg. 2007;84:1538-46.
52. Aylin P, Bottle A, Majeed A. Use of administrative data or clinical databases as predictors of risk of death in hospital: comparison of models. BMJ. 2007:334 1044

53. Karamlou T, Diggs BS, Ungerleider RM, Welke KF. Evolution of treatment options and outcomes for hypoplastic left heart syndrome over an 18-year period. $J$ Thorac Cardiovasc Surg. 2010;139:119-26.

54. Welke KF, Diggs BS, Karamlou T. Chance, bias, and confounding: threats to valid measurement of quality in the context of pediatric cardiac surgery. Semin Thorac Cardiovasc Surg Pediatr Card Surg Annu. 2010;13: 79-83.

55. Williams WG, McCrindle BW. Uses and limitations of registry and academic databases. Semin Thorac Cardiovasc Surg. 2010;13:66-70.

56. Society of Thoracic Surgeons. Society of Thoracic Surgeons executive summary report. Available at: https://www.sts.org/sites/default/files/Congenital-STSExec Summary AllPatients.pdf. Accessed July 29, 2020.

57. Gaies M, Anderson J, Kipps A, Lorts A, Madsen N, Marino B, et al. Cardiac networks united: an integrated paediatric and congenital cardiovascular research and improvement network. Cardiol Young. 2019;29:111-8.

58. Welke KF, Pasquali SK, Lin P, Backer CL, Overman DM, Romano JC, et al. Hospital distribution and patient travel patterns for congenital heart surgery in the United States. Ann Thorac Surg. 2019;107:574-81.

59. Welke KF, Pasquali SK, Lin P, Backer CL, Overman DM, Romano JC, et al. Regionalization of congenital heart surgery in the United States. Semin Thorac Cardiovasc Surg. 2020;32:128-37.

60. Agency for Healthcare Quality and Research. HCUP Databases. Healthcare Cost and Utilization Project (HCUP). Available at: https://www.hcup-us.ahrq.gov/ databases.jsp. Accessed June 14, 2020.

61. Mack MJ, Herbert M, Prince S, Dewey TM, Magee MJ, Edgerton JR. Does reporting of coronary artery bypass grafting from administrative databases accurately reflect actual clinical outcomes? J Thorac Cardiovasc Surg. 2005;129: 1309-17.

62. Jacobs JP, Edwards FH, Shahian DM, Haan CK, Puskas JD, Morales DLS, et al. Successful linking of the Society of Thoracic Surgeons adult cardiac surgery database to centers for medicare and medicaid services medicare data. Ann Thorac Surg. 2010;90:1150-7.

63. Jacobs JP, Edwards FH, Shahian DM, Prager RL, Wright CD, Puskas JD, et al Successful linking of the Society of Thoracic Surgeons database to social security data to examine survival after cardiac operations. Ann Thorac Surg. 2011;92: 32-9.

64. Jacobs JP, Shahian DM, He X, O'Brien SM, Badhwar V, Cleveland JC, et al Penetration, completeness, and representativeness of the Society of Thoracic Surgeons adult cardiac surgery database. Ann Thorac Surg. 2016 101:33-41.

65. Jacobs JP, Yohe C, Krantz J, Blackstone EH. Documentation of vital status in the United States of America. J Thorac Cardiovasc Surg. 2017;154 644-6.

66. Tong BC, Kim S, Kosinski A, Onaitis MW, Boffa DJ, Habib RH, et al. Penetration, completeness, and representativeness of the Society of Thoracic Surgeons general thoracic surgery database for lobectomy. Ann Thorac Surg. 2019;107: 897-902.

67. Nelson J, Maul T, Wearden P, Najm HK, Baloglu O, Johnston D, et al. Aortic valve replacement in young and middle-aged adults: current and potential roles of TAVR. Ann Thorac Surg. August 5, 2020 [Epub ahead of print].

68. Deutsch H. Psychology of Women. Volume One: Girlhood. London: Research Books; 1946.

Key Words: congenital cardiac surgery, database, outcomes 